\title{
Care for survivors of acute kidney injury
}

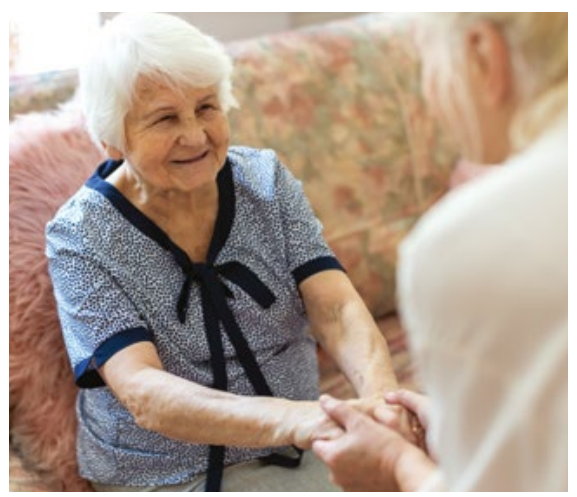

CPD

Timothy J Pianta, Zena Barakat, David Langsford

\section{Background}

The effects of acute kidney injury (AKI) extend beyond the acute illness phase. Patients who survive AKI are at increased risk of hospital readmission, chronic disease including kidney and cardiovascular disease, frailty and death. AKI may be overlooked among more obvious or complex healthcare concerns. While developing a cogent, systemic response to care after $A K I$ is a neglected public health priority, attention to several common challenges may improve patient outcomes.

\section{Objective}

The aim of this article is to highlight common challenges in managing survivors of $\mathrm{AKI}$ and offer suggestions to guide management.

\section{Discussion}

For clinicians managing survivors of AKI, identifying and communicating patient priorities, risk factors and comorbidities including a history of $\mathrm{AKI}$ is important. Concurrent management challenges include education regarding lifestyle and pharmacotherapy, managing medication interruptions and dose adjustments, and re-establishing a long-term management plan for chronic diseases.
ACUTE KIDNEY INJURY (AKI) is characterised by a rapid reduction in glomerular filtration rate (GFR) ${ }^{1}$ Criteria from the organisation Kidney Disease: Improving Global Outcomes (KDIGO) rely on an acute elevation in serum creatine (>26.5 $\mu \mathrm{mol}$ or $>50 \%$ from baseline) or oliguria to define AKI in adults and determine its severity from stage 1 ('mild') to stage 3 ('severe'). ${ }^{1}$ Without recent creatinine measurements, differentiating AKI from unrecognised CKD can be difficult, and urine output is often imprecisely measured. AKI affects $8-20 \%$ of adults admitted to hospital and approximately half of patients in intensive care units. ${ }^{2}$ Acute kidney replacement therapy (KRT) is initiated in approximately $1 \%$ of all hospitalised patients. ${ }^{3}$

AKI is a heterogenous syndrome but is often precipitated by extrarenal disease in at-risk patients. The classification of 'pre-renal, renal and post-renal' causes can ensure differential diagnoses are considered. The most common cause is acute tubular injury due to a combination of hypoperfusion, sepsis or medications that produce toxicity or compound hypoperfusion (eg antihypertensives). ${ }^{4}$ While AKI can occur in patients without underlying health problems, it is particularly common in elderly patients and those with comorbidity, particularly chronic kidney disease (CKD), heart failure and chronic liver disease (Figure 1).

There is a relationship between all stages of AKI and later morbidity and mortality, even when GFR returns to baseline. ${ }^{5}$ While higher rates of comorbidity in patients with AKI explain and mediate some of the poor outcomes seen, careful observation has shown that episodes of AKI are independently associated with adverse events for up to 10 years (Figure 1). ${ }^{1,6} \mathrm{By}$ 90 days, $20-29 \%$ of patients are readmitted to hospital. ${ }^{7,8}$ Adjusting for other factors, AKI approximately doubles the risk of subsequent death. ${ }^{9}$ In one large study examining survivors of AKI, 12-month mortality was $28 \% .{ }^{10}$ Common causes of death included cancer (28\%) and cardiovascular disease (CVD; 28\%), with mortality ratios reaching eight times those of the general population. ${ }^{10}$

The period after AKI represents an opportunity to improve care. ${ }^{6,11}$ However, lack of advocacy, resource and policy constraints, and competing health priorities limit the attention given to AKI. ${ }^{6}$ The benefit of specialist post-AKI clinics remains unproven. ${ }^{12}$ Thus, general practice represents the coalface of this important problem, particularly in rural and remote areas.

Few overarching guidelines address the period post-AKI. ${ }^{6,11}$ Although a UK 


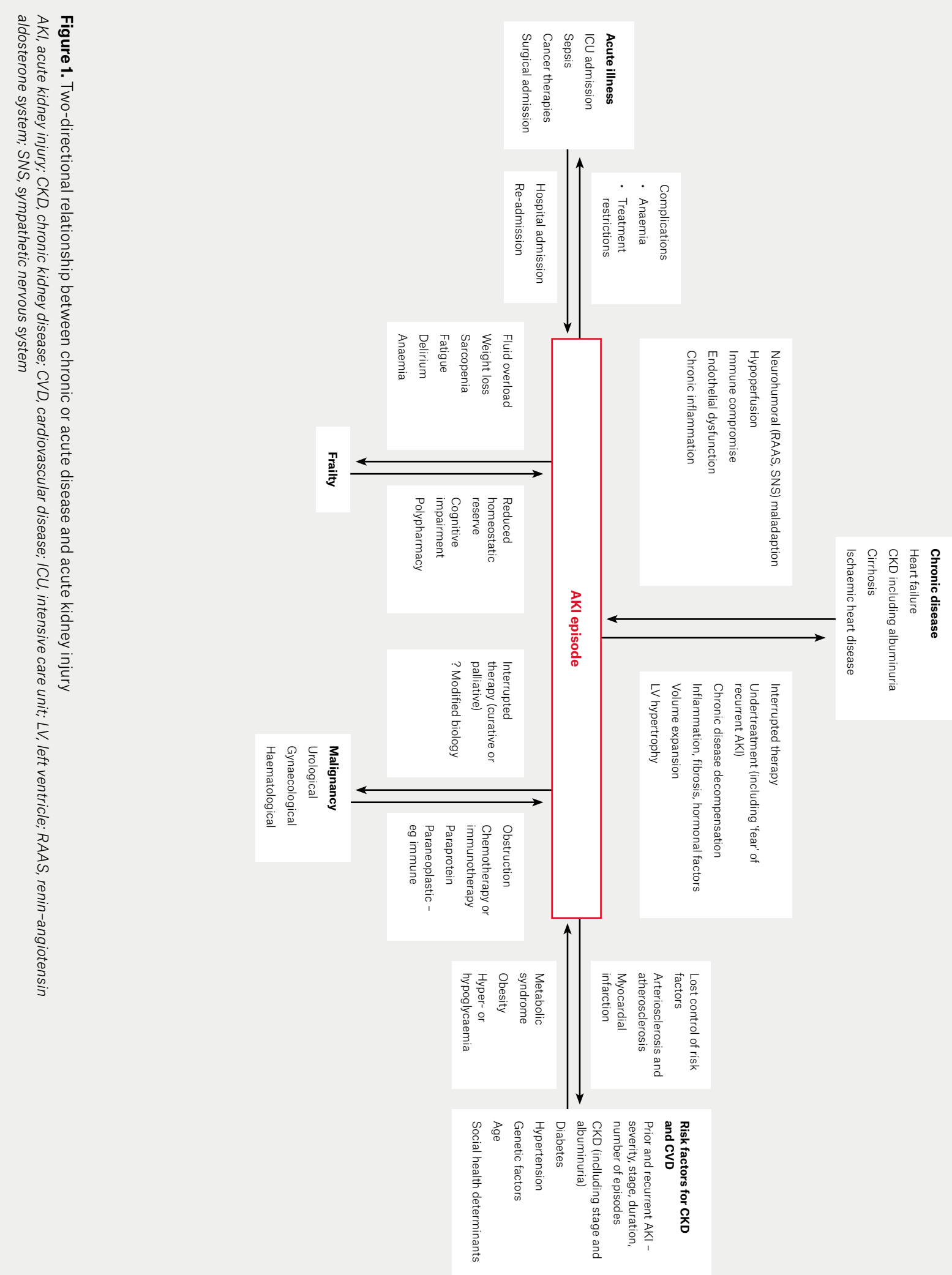


collaborative has developed an AKI Toolkit (www.rcgp.org.uk/aki) that includes discussion of post-AKI care, it has a distinct local perspective. The aim of this review is to highlight common challenges and offer suggestions to help guide the management of survivors of AKI. Table 1 provides a summary.

\section{Diagnostic priorities}

Communication and AKI

Synthesis of AKI into the patient history and management plans can inform screening, case-finding, prognosis and management. ${ }^{1,13}$ However, approximately half of AKI diagnoses in Australian inpatient settings are missed or poorly communicated at discharge, representing a practice and policy challenge. ${ }^{14}$ Incorporating AKI into decision support software is an attractive solution that is undergoing research. ${ }^{15}$

\section{Addressing the patient experience and complex care needs}

Small series examining patients' experiences of AKI report a desire for holistic care, education and quality of life ${ }^{6}$ Holistic care is important, as following AKI there is an increased prevalence of systemic problems including anaemia, ${ }^{16}$ infection ${ }^{17}$ and musculoskeletal disorders. ${ }^{18}$ Because

\section{Table 1. Suggested management priorities after acute kidney injury}

\begin{tabular}{|c|c|}
\hline \multicolumn{2}{|l|}{ Diagnosis } \\
\hline Documentation & $\begin{array}{l}\text { - Clarify whether patients and carers understand the } \\
\text { diagnosis of AKI. } \\
\text { - Document the AKI episode in medical records and } \\
\text { incorporate it into treatment plans. }\end{array}$ \\
\hline Address complexity & $\begin{array}{l}\text { - Clarify patient priorities, including holistic care, education } \\
\text { and quality of life. } \\
\text { - Recognise common issues 'beyond GFR' (eg persistent } \\
\text { effects of acute illness, anaemia, cognitive impairment } \\
\text { and frailty). }\end{array}$ \\
\hline Case-finding & $\begin{array}{l}\text { - Unrecognised CKD and cardiovascular disease, especially } \\
\text { heart failure, are common. } \\
\text { - Hypertension and diabetes may be unrecognised or } \\
\text { may emerge. }\end{array}$ \\
\hline Preventive healthcare & $\begin{array}{l}\text { - Revisit healthy lifestyle measures and immunisation. } \\
\text { - Screen for cardiovascular or CKD risk factors and } \\
\text { malignancy within existing guidelines. }\end{array}$ \\
\hline
\end{tabular}

Management challenges

\begin{tabular}{ll}
\hline Medication interruptions & Seek clarity about why medications have been interrupted \\
if this information is missing. \\
$\begin{array}{l}\text { - Timely medication adjustments reflecting further changes } \\
\text { in GFR (eg antimicrobials, anticoagulants, analgesia and } \\
\text { diabetes therapies). }\end{array}$
\end{tabular}

\begin{tabular}{ll}
$\begin{array}{l}\text { Chronic disease } \\
\text { management }\end{array}$ & - $P$ Permissive AKI': tolerate an acute GFR reduction to \\
& permit long-term benefit. \\
\hline Sick-day advice & - Identify medications that might accumulate dangerously, \\
& or exacerbate hypoperfusion, renal toxicity or \\
& hyperkalaemia with acute illness. \\
- Sick-day medication interruptions should be accompanied & by prompt review (eg to recognise unanticipated \\
& hypertension or hyperglycaemia). \\
\hline
\end{tabular}

AKI, acute kidney injury; CKD, chronic kidney disease; GFR, glomerular filtration rate

AKI often accompanies complex admissions and comorbidity, ${ }^{19}$ a narrow focus on GFR or volume state may fragment care and produce poor outcomes. For example, palliative care services are underutilised by patients with AKI. ${ }^{20}$

Frailty is a distinct risk factor for, and potential consequence of, $\mathrm{AKI}^{21,22}$ and increases the risk of subsequent death. ${ }^{10}$ The interplay between AKI and frailty encompasses comorbidity and complications of AKI. Figure 1 illustrates some potentially modifiable elements.

\section{Screening and case-finding: Cardiovascular or CKD risk factors}

Review after AKI may unearth modifiable risk factors for CVD and CKD. Diabetes is prevalent among survivors of $\mathrm{AKI},{ }^{23}$ but potentially unrecognised ${ }^{24}$ and new-onset diabetes is independently increased in survivors of AKI. ${ }^{25} \mathrm{AKI}$ also predisposes to subsequent hypertension. ${ }^{26,27}$

Diagnostic guidelines for diabetes recommend case-finding after a CVD event but do not cover case-finding for diabetes $^{28}$ or hypertension after AKI. ${ }^{27,29}$ These authors suggest case-finding for diabetes and hypertension after an AKI episode. Many patients will warrant longer-term case-finding as well as lipid assessment on the basis of existing risk factors and guidelines.

\section{AKI, CKD and acute kidney disease}

$\mathrm{AKI}$ and $\mathrm{CKD}$ are interconnected, sharing risk factors, outcomes and prognostic factors. ${ }^{30,31}$ Both disorders indicate an increased likelihood of subsequent AKI, kidney failure, CVD, diminished quality of life, disability and death. Prognosis is affected by the duration and number of AKI episodes and the stage of either AKI or CKD (Figure 1). ${ }^{30}$

When features of AKI persist between seven and 90 days, the term acute kidney disease can be applied, ${ }^{31}$ although this terminology is not widely used. CKD is defined by an estimated GFR (eGFR) $<60 \mathrm{~mL} / \mathrm{min} / 1.73 \mathrm{~m}^{2}$ or evidence of kidney damage (eg albuminuria, haematuria, or structural or pathological abnormalities) for $\geq 3$ months and is staged according to eGFR and albuminuria. ${ }^{13,32}$ 
While eGFR and albuminuria estimation at three months post-AKI is appropriate, ${ }^{31}$ earlier review may uncover CKD, thus far unrecognised because of a lack of healthcare engagement or CKD screening, or a failure to communicate or interpret historical results. ${ }^{6,23} \mathrm{AKI}$ is also appropriately included among eight triggers to initiate ongoing kidney health checks. ${ }^{13}$

\section{Heart failure and cardiovascular disease}

The bidirectional relationship between heart failure and AKI or CKD is termed 'cardiorenal syndrome', ${ }^{33}$ with shared risk factors and pathophysiology (Figure 1). AKI and CKD both predict incident heart failure. ${ }^{34}$ After AKI, concurrent heart failure increases the risk of early readmission; ${ }^{29,35}$ overall, acute decompensated heart failure is the most common cause of hospital readmission. ${ }^{19,36}$

Established or new presentations of ischaemic heart disease are also common. For patients with ischaemic heart disease, the presence of AKI is similarly associated with greater readmission rates and complications. ${ }^{37}$

\section{Malignancy}

The high incidence of death from malignancy noted after $\mathrm{AKI}^{10}$ is intriguing and potentially challenges the existing focus on CKD, CVD and metabolic factors (Figure 1). However, most cancers are known at the time of AKI, ${ }^{10}$ and applying existing cancer screening recommendations currently seems appropriate.

\section{Management priorities}

\section{Healthy lifestyle and immunisation}

Lifestyle is a cornerstone of good health. Physical activity, healthy diet, salt minimisation, weight optimisation, smoking cessation, appropriate vaccination (especially influenza, pneumococcus and COVID-19) ${ }^{38}$ and alcohol reduction underpin any pharmacotherapy ${ }^{6,13}$ and may help prevent rehospitalisation. ${ }^{39}$

Evidence-based resources that encourage independence and healthy eating are usually suitable. ${ }^{40}$ However, conflicting advice may confuse patients. For example, strategies to limit dietary potassium in patients at highest risk of hyperkalaemia ${ }^{41}$ may inadvertently direct patients away from diets rich in fruit and vegetables, which reduce the development of CKD, constipation and metabolic acidosis (all of which can worsen hyperkalaemia), as well as hypertension. ${ }^{41-44}$ Counselling from accredited dietitians is likely useful to help manage suspected nutritional deficiency or persistent hyperkalaemia.

\section{Managing medication interruptions}

Despite limited evidence, medication interruptions are common in patients with AKI. ${ }^{1,4,31}$ Commonly, such interruptions aim to avoid:

- pharmacokinetic concerns

- medication accumulation with reduced GFR

- pharmacodynamic concerns

- worsening AKI via systemic and renal hypoperfusion

- worsening AKI by direct toxicity

- exacerbating hyperkalaemia, hyperglycaemia, hypoglycaemia or other metabolic disturbances accompanying AKI. ${ }^{4,45}$

Just as adjustment to medications should accompany a fall in GFR, there must be timely adjustment as GFR recovers. Antimicrobials and anticoagulants are commonly renally cleared and warrant particular attention to avoid critical therapeutic failures.

For patients with unresolved oliguria, advanced CKD or heart failure, volume control can be helped by redefining a weight-based trigger for medical review, and potentially fluid restriction or a diuretic sliding scale. ${ }^{46}$ Interim 'standard' blood pressure targets $(<140 / 90 \mathrm{mmHg})$ are likely appropriate until recovery is complete, recognising the significant benefits of lower long-term targets for many patients. ${ }^{29,35}$

Medication interruption may be poorly explained or accompanied by vague directions to 'avoid nephrotoxics' without further clarification. Clarifying the instructions and optimising important medications is an important task after AKI. ${ }^{45}$
Just how medication review affects post-AKI outcomes is unclear. International panels ${ }^{31,47}$ have recommended prioritising review - within as little as three days on the basis of AKI stage, poorer GFR recovery, comorbidity (particularly heart failure) and functional impairment. These recommendations presuppose recognition and communication of AKI diagnoses and may be difficult to accommodate in systems geared to chronic care. Research clarifying the early role of telemedicine, deprescribing tools, pharmacists, nurse practitioners, physicians and general practitioners (GPs) in providing optimal and cost-effective care is justified. ${ }^{6,31}$

\section{Permissive AKI}

Strategies that address volume control, hypertension and neurohumoral factors are often feared because of a perceived tension between the heart and kidneys. ${ }^{48}$ One example is the use of angiotensin converting enzyme (ACE) inhibitors or angiotensin receptor blockers (ARBs) in the management of heart failure with reduced ejection fraction (HFrEF). ${ }^{49,50}$

More strategies that present similar tensions in addition to important prognostic benefits have recently arrived. These include assertive hypertension management in selected patients at high cardiovascular risk, ${ }^{29,35}$ combined angiotensin receptor-neprilysin inhibitors (ARNIs) in $\mathrm{HFrEF}^{48}$ sodium-glucose co-transporter-2 (SGLT2) inhibitors in $\mathrm{HFrEF}$ or CKD, ${ }^{51-53}$ and specific mineralocorticoid receptor antagonists (MRAs) for CKD. ${ }^{54}$

Concern about recurrent $\mathrm{AKI}$ is understandable, and acute falls in GFR are common when introducing these strategies and in the natural history of heart failure. ${ }^{48,55}$ However, while these treatment-related falls in GFR may meet formal definitions of AKI, they appear not to produce the long-term harms common to AKI overall. ${ }^{48,55}$ Generally, these strategies improve important long-term CKD outcomes ${ }^{51-54,56,57}$ or have 'extrarenal' benefits such as reducing the incidence of stroke. ${ }^{29,35}$ Specifically, despite concerns regarding hypoperfusion and a predictable effect 
on GFR with initiation, neither SGLT2 inhibitor, ACE inhibitor nor ARB prescription appears to increase the overall risk for recurrent AKI. ${ }^{58-60}$

The term 'permissive AKI' has been coined to describe acceptance of a potential reduction in GFR to minimise long-term CVD or CKD. ${ }^{48}$ Patients can be reassured that a fall in GFR is acceptable if:

- the decline in GFR is anticipated

- there are no alternative explanations (eg infection, gastrointestinal losses, true nephrotoxics)

- there is an important likely benefit (eg slowing CKD progression or CVD)

- no other important complications emerge (eg hyperkalaemia, acidosis, potential medication toxicity)

- there is a sensible monitoring plan for detecting complications. ${ }^{48}$

Despite a 'permissive' strategy, monitoring of potassium and GFR remains important, particularly to inform dosing of renally cleared medications (eg pregabalin). The risk of medication interactions and polypharmacy must be balanced with potential benefits. Without clear evidence regarding the introduction of combination therapy, it seems prudent to introduce or re-introduce these medications sequentially and titrate to target doses.

Clinical and biochemical review within two weeks of medication changes will usually be appropriate. ${ }^{13,61}$ The use of novel potassium binders (eg patiromer) to offset medication-related hyperkalaemia has been proposed ${ }^{62}$ but is not established or subsidised by the Pharmaceutical Benefits Scheme.

\section{Heart failure after AKI}

Extensive guidelines, beyond the scope of this review, frame the management of heart failure. ${ }^{46}$ However, beyond fluid and hypertension control, particular priorities for AKI survivors with heart failure include:

- improving access to multidisciplinary management, particularly for patients at high risk of rehospitalisation ${ }^{46}$

- optimising medication strategies with prognostic benefit, including ACE inhibitors/ARBs and vasodilatory $\beta$-blockers for HFrEF. Subsequent, evidence-based use of medications with diuretic effects (ARNIs, MRAs and SGLT2 inhibitors) will often make reduction or cessation of loop or thiazide diuretics - not clearly associated with mortality benefits possible and appropriate. ${ }^{46}$

\section{Diabetes after AKI}

Recent changes to glucose-lowering medications - especially temporary or new use of insulin - present distinct challenges. Ensuring safe insulin administration and adjustment, self-monitoring of blood glucose, avoidance of hypoglycaemia, and fitness to drive are early priorities. Prompt referral to a credentialled diabetes nurse educator (DNE) may complement medical input. ${ }^{63}$

\section{Sick-day advice}

The provision of 'sick-day advice' also lacks robust evidence of benefit. ${ }^{64,65}$ However, it appears prudent for patients at high risk of recurrent AKI. These authors suggest the following.

- Identify medications with risk of hypoperfusion, dangerous accumulation, toxicity or exacerbating hyperkalaemia. Mnemonics highlighting some high-risk medications (eg 'SADMANS' for sulfonylureas, ACE inhibitors, diuretics, metformin, ARBs, NSAIDs and SGLT2 inhibitors) are offered within CKD guidelines as prompts; ${ }^{13}$ however, other glucoselowering medications, antivirals, anticoagulants, antiarrhythmics, analgesics and sedative medications are particularly prone to acute accumulation ${ }^{66}$ and should be considered as high-risk medications in the setting of AKI.

- Instruct patients to withhold such medications when they experience vomiting, diarrhoea, reduced oral intake or other serious illness.

- Provide permission and instruction to seek prompt medical attention, because - acute illness, including AKI, may paradoxically produce hypertension and hyperglycaemia, warranting an escalation of specific therapies

- vulnerable patients often need further medical interventions on 'sick days' ${ }^{64}$

Advice should balance the risks and benefits of briefly stopping medications; be individualised; include translation, written instructions or visual aids; consider existing strategies for chronic medications (eg Webster Packs); and involve carers and other clinicians, including pharmacists.

\section{The big picture}

Most patients are not cared for by a nephrologist during or after AKI. Currently the predominant reasons for nephrology referral are ongoing KRT, immune- or paraprotein-mediated AKI or existing CKD. Most nephrology clinics and guidelines remain oriented to such problems. ${ }^{13}$ International resources should be better adapted to suit local perspectives.

While GPs excel at holistic care, selected patients probably benefit from non-GP specialist services after an episode of AKI. ${ }^{67}$ This includes patients requiring specialised medications (eg potassium binders), allied healthcare (eg renal dietitians) and diseaseoriented services (eg DNEs or heart failure clinics). Further efforts should define the best model of care for AKI survivors and better integrate research into chronic disease guidelines and existing services.

\section{Conclusion}

Patients who survive AKI are at high risk of hospital readmission and death, particularly over the following year. Attention to several common areas is likely to improve individual patient outcomes.

\section{Key points}

- AKI increases the risk of hospital readmission, kidney disease, CVD, disability, frailty and death.

- Several diseases are recognised as risk factors for and potentially underlie AKI, including $\mathrm{CKD}$, cardiovascular risk or disease, and possibly malignancy.

- The acute response to AKI often involves withholding or reducing the doses of medications that may have important long-term prognostic benefits. Rational reintroduction and dose adjustment of medications - mindful of polypharmacy and toxicity - is a complex but important task.

- Improved outcomes after AKI likely require improved policies and 


\section{clinical structures to provide timely, coordinated and optimal care to the patients at greatest need.}

\section{Authors}

Timothy J Pianta MBBS (Hons), PhD, FRACP, Nephrologist, Northern Health, Vic; Senior Lecturer, Department of Medical Education, University of Melbourne, Vic

Zena Barakat MD, Basic Physician Trainee, Northern Health, Vic: Northern Clinical School, University of Melbourne, Vic

David Langsford MBBS (Hons), PhD, FRACP, Head of Obstetric Medicine Unit and Nephrologist, Director of Physician Education, Northern Health, Vic; Lecturer, Northern Clinical School, University of Melbourne, Vic Competing interests: None.

Funding: None.

Provenance and peer review: Commissioned, externally peer reviewed.

\section{Correspondence to:}

timothy.pianta@nh.org.au

\section{References}

1. Kidney Disease: Improving Global Outcomes (KDIGO) Acute Kidney Injury Work Group. KDIGO clinical practice guideline for acute kidney injury. Kidney Inter Suppl 2012;2:1-138. doi: 10.1038/ kisup.2012.1

2. Susantitaphong P, Cruz DN, Cerda J, et al. World incidence of AKI: A meta-analysis. Clin J Am Soc Nephrol 2013;8(9):1482-93. doi: 10.2215/ CJN.00710113.

3. Prescott GJ, Metcalfe W, Baharani J, et al. A prospective national study of acute renal failure treated with RRT: Incidence, aetiology and outcomes. Nephrol Dial Transplant 2007;22(9):2513-19. doi: 10.1093/ndt/gfm264.

4. Pianta TJ, Buckley NA, Peake PW, Endre ZH. Clinical use of biomarkers for toxicant-induced acute kidney injury. Biomark Med 2013;7(3):441-56. doi: 10.2217/bmm.13.51.

5. Sawhney S, Marks A, Fluck N, Levin A, Prescott G, Black C. Intermediate and long-term outcomes of survivors of acute kidney injury episodes: A large population-based cohort study. Am J Kidney Dis 2017;69(1):18-28. doi: 10.1053/j.ajkd.2016.05.018.

6. Siew ED, Liu KD, Bonn J, et al. Improving care for patients after hospitalization with AKI. J Am Soc Nephrol 2020;31(10):2237-41. doi: 10.1681/ ASN.2020040397.

7. Sawhney S, Marks A, Fluck N, McLernon DJ, Prescott GJ, Black C. Acute kidney injury as an independent risk factor for unplanned 90-day hospital readmissions. BMC Nephrol 2017;18(1):9 doi: 10.1186/s12882-016-0430-4.

8. Koulouridis I, Price LL, Madias NE, Jaber BL. Hospital-acquired acute kidney injury and hospital readmission: A cohort study. Am J Kidney Dis 2015;65(2):275-82. doi: 10.1053/j. ajkd.2014.08.024.

9. Coca SG, Singanamala S, Parikh CR. Chronic kidney disease after acute kidney injury: A systematic review and meta-analysis. Kidney Int 2012;81(5):442-48. doi: 10.1038/ki.2011.379.

10. Silver SA, Harel Z, McArthur E, et al. Causes of death after a hospitalization with AKI. J Am Soc Nephrol 2018;29(3):1001-10. doi: 10.1681/ ASN.2017080882.

11. Silver SA, Goldstein SL, Harel Z, et al. Ambulatory care after acute kidney injury: An opportunity to improve patient outcomes. Can J Kidney Health Dis 2015:2:36. doi: 10.1186/s40697-015-0071-8.

12. Horne KL, Shardlow A, Taal MW, Selby NM. Long term outcomes after acute kidney injury: Lessons from the ARID study. Nephron 2015;131(2):102-06. doi: 10.1159/000439066.

13. Kidney Health Australia. Chronic kidney disease (CKD): Management in primary care. 4th edn. Melbourne, Vic: Kidney Health Australia, 2020.

14. Campbell CA, Li L, Kotwal S, et al. Underdetection of acute kidney injury in hospitalised patients: A retrospective, multi-site, longitudinal study. Intern Med J 2020;50(3):307-14 doi: 10.1111/imj.14264.

15. Chiang J, Furler J, Boyle D, Clark M Manski-Nankervis JA. Electronic clinical decision support tool for the evaluation of cardiovascular risk in general practice: A pilot study. Aust Fam Physician 2017;46(10):764-68.

16. Liangos O, Pereira BJG, Jaber BL. Anemia in acute renal failure: Role for erythropoiesis-stimulating proteins? Artif Organs 2003:27(9):786-91. doi: 10.1046/j.1525-1594.2003.07287.x

17. Gist KM, Faubel S. Infection post-AKI: Should we worry? Nephron 2020 44(12):673-76. doi: 10.1159/000508101.

18. Johnson RJ, Bakris GL, Borghi C, et al. Hyperuricemia, acute and chronic kidney disease, hypertension, and cardiovascular disease: Report of a scientific workshop organized by the national kidney foundation. Am J Kidney Dis 2018;71(6):851-65. doi: 10.1053/j.ajkd.2017.12.009.

19. Siew ED, Davenport A. The growth of acute kidney injury: A rising tide or just closer attention to detail? Kidney Int 2015;87(1):46-61. doi: 10.1038/ ki.2014.293.

20. Chong K, Silver SA, Long J, et al. Infrequent provision of palliative care to patients with dialysis-requiring AKI. Clin J Am Soc Nephrol 2017;12(11):1744-52. doi: 10.2215/CJN.00270117.

21. Abdel-Kader K, Girard TD, Brummel NE, et al. Acute kidney injury and subsequent frailty status in survivors of critical illness. Crit Care Med 2018:46(5):e380-e88. doi: 10.1097/ CCM.0000000000003003

22. Vanmassenhove J, Van Biesen W, Lameire N. The interplay and interaction between frailty and acute kidney injury. Nephrol Dial Transplant 2020;35(6):911-15. doi: 10.1093/ndt/gfz275.

23. Barakat Z, Langsford D, Pianta T. Diagnosis and referral to nephrology services of inpatients with acute kidney injury (Abstract). Nephrology (Carlton) 2018;23(Suppl 3):69.

24. Nanayakkara N, Nguyen $H$, Churilov L, et al. Inpatient $\mathrm{HbA} 1 \mathrm{c}$ testing: A prospective observational study. BMJ Open Diab Res Care 2015;3(1):e000113. doi: 10.1136/bmjdrc-2015000113.

25. Lin YF, Lin SL, Huang TM, et al. New-onset diabetes after acute kidney injury requiring dialysis. Diabetes Care 2018:41(10):2105-10. doi: 10.2337/dc17-2409.

26. Hsu CY, Hsu RK, Yang J, Ordonez JD, Zheng $S$, Go AS. Elevated BP after AKI. J Am Soc Nephrol 2016;27(3):914-23. doi: 10.1681/ASN.2014111114.

27. Whelton PK, Carey RM, Aronow WS, et al. 2017 ACC/AHA/AAPA/ABC/ACPM/AGS/APhA/ASH/ ASPC/NMA/PCNA guideline for the prevention, detection, evaluation, and management of high blood pressure in adults: A report of the American College of Cardiology/American Heart Association task force on clinical practice guidelines. Hypertension 2018;71(6):e116. doi: 10.1161/ HYP.0000000000000066.
28. Colagiuri S, Davies D, Girgis S, Colagiuri R National evidence based guideline for case detection and diagnosis of type 2 diabetes. Canberra, ACT: Diabetes Australia and the NHMRC, 2009

29. Gabb GM, Mangoni AA, Anderson CS, et al. Guideline for the diagnosis and management of hypertension in adults - 2016. Med J Aust 2016;205(2):85-89. doi: 10.5694/mja16.00526.

30. Chawla LS, Eggers PW, Star RA, Kimmel PL. Acute kidney injury and chronic kidney disease as interconnected syndromes. N Engl J Med 2014;371(1):58-66. doi: 10.1056/NEJMra1214243.

31. Chawla LS, Bellomo R, Bihorac A, et al. Acute kidney disease and renal recovery: Consensus report of the Acute Disease Quality Initiative (ADQI) 16 workgroup. Nat Rev Nephol 2017:13(4):241-57. doi: 10.1038/nrneph.2017.2.

32. Kidney Disease: Improving Global Outcomes (KDIGO) CKD Work Group. KDIGO 2012 clinical practice guideline for the evaluation and management of chronic kidney disease. Kidney Int Suppl 2013;3(1):1-150. doi: 10.1038/kisup.2012.72.

33. Ronco C, Haapio M, House AA, Anavekar N, Bellomo R. Cardiorenal syndrome. J Am Coll Cardiol 2008;52(19):1527-39. doi: 10.1016/j. jacc.2008.07.051.

34. Kottgen A, Russell SD, Loehr LR, et al. Reduced kidney function as a risk factor for incident heart ailure: The Atherosclerosis Risk In Communities (ARIC) study. J Am Soc Nephrol 2007;18(4):1307-15. doi: 10.1681/ASN.2006101159.

35. Wright JT Jr, Williamson JD, Whelton PK, et al. A randomized trial of intensive versus standard blood-pressure control. N Engl J Med 2015;373(22):2103-16. doi: 10.1056/ NEJMoa1511939

36. Silver SA, Harel Z, McArthur E, et al. 30-day readmissions after an acute kidney injury hospitalization. Am J Med 2017;130(2):163-72.e4 doi: 10.1016/j.amjmed.2016.09.016

37. Marenzi G, Cosentino N, Bartorelli AL. Acute kidney injury in patients with acute coronary syndromes. Heart 2015;101(22):1778-85. doi: 10.1136/heartjnl-2015-307773.

38. Australian Technical Advisory Group on Immunisation (ATAGI). Australian immunisation handbook. Canberra, ACT: DoH, 2018.

39. Mullen KA, Manuel DG, Hawken SJ, et al. Effectiveness of a hospital-initiated smoking cessation programme: 2-year health and healthcare outcomes. Tob Control 2017;26(3):293-99. doi: 10.1136/ tobaccocontrol-2015-052728.

40. National Health and Medical Research Council. Australian dietary guidelines. Canberra, ACT: NHMRC, 2013.

41. Kalantar-Zadeh K, Fouque D. Nutritional management of chronic kidney disease. N Engl J Med 2017;377(18):1765-76. doi: 10.1056/ NEJMra1700312.

42. Appel LJ, Moore TJ, Obarzanek E, et al. A clinical trial of the effects of dietary patterns on blood pressure. DASH collaborative research group. N Engl J Med 1997;336(16):1117-24. doi: 10.1056/ NEJM199704173361601.

43. Jhee JH, Kee YK, Park JT, et al. A diet rich in vegetables and fruit and incident CKD: A community-based prospective cohort study. Am J Kidney Dis 2019;74(4):491-500. doi: 10.1053/j. ajkd.2019.02.023.

44. Goraya N, Simoni J, Jo CH, Wesson DE. A comparison of treating metabolic acidosis in CKD stage 4 hypertensive kidney disease with 
fruits and vegetables or sodium bicarbonate. Clin J Am Soc Nephrol 2013;8(3):371-81. doi: 10.2215/ CJN.02430312.

45. Jones M, Tomson C. Acute kidney injury and 'nephrotoxins': Mind your language. Clin Med (Lond) 2018;18(5):384-86. doi: 10.7861/ clinmedicine.18-5-384.

46. Atherton JJ, Sindone A, De Pasquale CG, et al. National Heart Foundation of Australia and Cardiac Society of Australia and New Zealand: Guidelines for the prevention, detection, and management of heart failure in Australia 2018. Heart Lung Circ 2018;27(10):1123-208. doi: 10.1016/j.hlc.2018.06.1042.

47. Tsang JY, Murray J, Kingdon E, et al. Guidance for post-discharge care following acute kidney injury: An appropriateness ratings evaluation. BJGP Open 2020;4(3):bjgpopen20X101054. doi: 10.3399/ bjgpopen20X101054.

48. Parikh CR, Coca SG. 'Permissive AKI' with treatment of heart failure. Kidney Int 2019;96(5):1066-68. doi: 10.1016/j. kint.2019.07.003.

49. Pitt B, Zannad F, Remme WJ, et al. The effect of spironolactone on morbidity and mortality in patients with severe heart failure. Randomized aldactone evaluation study investigators. N Engl J Med 1999;341(10):709-17. doi: 10.1056/ NEJM199909023411001.

50. Cohn JN, Tognoni G. A randomized trial of the angiotensin-receptor blocker valsartan in chronic heart failure. N Engl J Med 2001;345(23):1667-75. doi: 10.1056/NEJMoa010713.

51. Wanner C, Inzucchi SE, Lachin JM, et al. Empagliflozin and progression of kidney disease in type 2 diabetes. N Engl J Med 2016;375(4):323-34. doi: 10.1056/NEJMoa1515920.

52. Perkovic $\mathrm{V}$, Jardine MJ, Neal B, et al. Canagliflozin and renal outcomes in type 2 diabetes and nephropathy. N Engl J Med 2019;380(24):2295-306. doi: 10.1056/ NEJMoa1811744.

53. Heerspink HJL, Stefánsson BV, Correa-Rotter R, et al. Dapagliflozin in patients with chronic kidney disease. N Engl J Med 2020;383(15):1436-46. doi: 10.1056/NEJMoa2024816.

54. Bakris GL, Agarwal R, Anker SD, et al. Effect of finerenone on chronic kidney disease outcomes in type 2 diabetes. N Engl J Med 2020;383(23):2219-29. doi: 10.1056/ NEJMoa2025845.

55. McCallum W, Tighiouart H, Ku E, Salem D, Sarnak MJ. Acute declines in estimated glomerular filtration rate on enalapril and mortality and cardiovascular outcomes in patients with heart failure with reduced ejection fraction. Kidney Int 2019;96(5):1185-94. doi: 10.1016/j. kint.2019.05.019.

56. Packer M, Claggett B, Lefkowitz MP, et al. Effect of neprilysin inhibition on renal function in patients with type 2 diabetes and chronic heart failure who are receiving target doses of inhibitors of the renin-angiotensin system: A secondary analysis of the PARADIGM-HF trial. Lancet Diabetes Endocrinol 2018;6(7):547-54. doi: 10.1016/S22138587(18)30100-1.

57. Wei L, Struthers AD, Fahey T, Watson AD, MacDonald TM. Spironolactone use and renal toxicity: Population based longitudinal analysis. BMJ 2010 340:c1768. doi: 10.1136/bmj.c1768.

58. Rampersad C, Kraut E, Whitlock RH, et al. Acute kidney injury events in patients with type 2 diabetes using SGLT2 inhibitors versus other glucose-lowering drugs: A retrospective cohort study. Am J Kidney Dis 2020;76(4):471-71.e1. doi: 10.1053/j.ajkd.2020.03.019.
59. Neuen BL, Young T, Heerspink HJL, et al. SGLT2 inhibitors for the prevention of kidney failure in patients with type 2 diabetes: A systematic review and meta-analysis. Lancet Diabetes Endocrinol 2019;7(11):845-54. doi: 10.1016/S22138587(19)30256-6.

60. Hsu CY, Liu KD, Yang J, et al. Renin-angiotensin system blockade after acute kidney injury (AKI) and risk of recurrent AKI. Clin J Am Soc Nephrol 2020;15(1):26-34. doi: 10.2215/CJN.05800519.

61. National Institute for Health and Care Excellence. Chronic kidney disease in adults: Assessment and management. London, UK: NICE, 2015.

62. Weir MR, Bushinsky DA, Benton WW, et al. Effect of patiromer on hyperkalemia recurrence in older chronic kidney disease patients taking RAAS inhibitors. Am J Med 2018;131(5):555-64.e3. doi: 10.1016/j.amjmed.2017.11.011.

63. Chin G, Robins R, Teaching patients with type 2 diabetes to self-administer insulin. Aust J Gen Pract 2019;48(5):251-54. doi: 10.31128/AJGP-1118-4764.

64. Martindale AM, Elvey R, Howard SJ, McCorkindale S, Sinha S, Blakeman T. Understanding the implementation of 'sick day guidance' to prevent acute kidney injury across a primary care setting in England: A qualitative evaluation. BMJ Open 2017;7(11):e017241-12. doi: 10.1136/bmjopen-2017-017241.

65. Hines A, Li X, Ortiz-Soriano V, et al. Use of angiotensin-converting enzyme inhibitors/ angiotensin receptor blockers and acute kidney disease after an episode of $\mathrm{AKI}$ : A multicenter prospective cohort study. Am J Nephrol 2020;51(4):266-75. doi: 10.1159/000505893.

66. Manski-Nankervis JA, McMorrow R, Nelson C, Jesudason S, Sluggett JK. Prescribing and deprescribing in chronic kidney disease. Aust J Gen Pract 2021;50(4):183-87. doi: 10.31128/AJGP11-20-5752.

67. Harel Z, Wald R, Bargman JM, et al. Nephrologist follow-up improves all-cause mortality of severe acute kidney injury survivors. Kidney Int 2013;83(5):901-08. doi: 10.1038/ki.2012.451. 